Die alkoholische Reactionsflüssigkeit enthält das Kaliumsalz der Säure. Sie wurde mit verdünnter Salzsäure schwach angesäuert, eingedampft und das entstandene salzsaure Salz der Säure mit absolutem Alkohol aufgenommen. Das aus diesem dargestellte Platinsalz zeigt nach dem Umkrystallisiren aus Alkohol gelbe Blättchen vom Schmelzpunkt $204^{\circ}$.

$\left(\mathrm{C}_{14} \mathrm{H}_{11} \mathrm{NO}_{2} . \mathrm{HCl}\right)_{2} \mathrm{PtCl}_{4}$. Ber. Pt 23.8. Gef. Pt 23.65.

468. O. Bialon: Ueber die Einwirkung ron Anisaldehyd auf Chinaldin, $\alpha$-Picolin und Aldehydcollidin.

[Aus dem chemischen Institut der Universität Breslau.]

(Eingegangen am 14. Juli 1902.)

Auf Veranlassung des Hrn. Geheimrath Ladenburg unternahm ich es, Anisaldehyd mit einigen $\alpha$-substituirten Pyridin- und ChinolinDerivaten zu condensiren.

\title{
I. Anisyliden-Chinaldin.
}

$10 \mathrm{~g}$ Chinaldin warden mit $8 \mathrm{~g}$ Anisaldehyd und einer Spur Chlorzink im zugeschmolzenen Rohre $10 \mathrm{Stdn}$. lang anf $180^{\circ}$ erhitzt. Das Reactionsproduct bildete ein festes, braunes Harz, das abgespaltene Wasser war im Rohre sichtbar; Druck war beim Oeffnen der Röhre nicht bemerkbar. Die Harzstücke wurden zerkleinert und mit verdünnter Salzsäure ausgekocht, wobei sie sich vollständig auflösten. Die Lösung wurde mit Aether ausgeschüttelt und auf dem Wasserbade eingeengt. Beim Erkalten fiel das Chlorhydrat in gelben Nadeln ans. Die Base schied sich beim Zusatz von festem Kali zur Lösung des salzsauren Salzes in graugrünen Flocken ab. Dieselben wurden mehrere Male aus heissem Alkohol umkrystallisirt, wonach sie beim Erkalten in weissen, glänzenden Blättchen vom Schmp. $126^{\circ}$ ausfielen. Die Ausbeute ist fast quantitativ. Die entstandene Base hat die Formel: $\mathrm{C}_{9} \mathrm{H}_{6} \mathrm{~N}$. CH: $\mathrm{CH} . \mathrm{C}_{6} \mathrm{H}_{4}\left(\mathrm{OCH}_{3}\right)$.

$$
\begin{aligned}
& \mathrm{C}_{18} \mathrm{H}_{15} \mathrm{ON} \text {. Ber. C } 82.75 \text {, H 5.74, N } 5.40 \text {. } \\
& \text { Gef. จ } 82.60 \text {, } 5.61 \text {, } 5.71 \text {. }
\end{aligned}
$$

Das Chlorhydrat bildet feine, gelbe Nadeln und wird aus Wasser umkrystallisirt. Schmp. 2080.

$$
\begin{aligned}
& \text { Ber. C 72.60, H 5.40. } \\
& \text { Gef. " 72.72, " 5.31. }
\end{aligned}
$$

Das Platindoppelsalz fällt in gelben Flocken aus, für die kein Krystallisationsmittel aufgefunden wurde. Es wurde daher aus reinem Material dargestellt. Schmp. $254^{\circ}$.

Ber. Pt 20.8. Gef. Pt 20.6. 
Das Golddoppelsalz bildet gelbe Flocken, welche aus verdünnter Salzsänre umkrystallisirt wurden. Schmp. $199^{\circ}$.

Ber. Au 32.8. Gef. Au 33.0.

Das Pikrat bildet nach dem Umkrystallisiren aus Aceton gelbe Nadeln, konnte aber nicht analysenrein erhalten werden.

Es wurde sodann die Base nach Ladenburg's Methode durch Natrium und absoluten Alkohol reducirt.

$10 \mathrm{~g}$ reine Base wurden in absolutem Alkohol gelöst und zu der in einem grossen Rundkolben mit langem Rückflusskühler befindlichen Lösung langsam $30 \mathrm{~g}$ Natrium zugesetzt. Nach Beendigung der Reaction wurde der Kolbeninhalt mit Wasser versetzt, wobei sich der grösste Theil der reducirten Base in gelben Flocken abschied. Nach dem Abdestilliren des Alkohols schied sich noch der Rest der Base ab, die, aus heissem Alkohol umkrystallisirt, in schönen, langen weissen Nadeln von seidenartigem Glanze ausfiel. Schmp. $71^{\circ}$. Formel: $\mathrm{C}_{9} \mathrm{H}_{10} \mathrm{~N} \cdot \mathrm{CH}_{2} \cdot \mathrm{CH}_{2} \cdot \mathrm{C}_{6} \mathrm{H}_{4} \cdot \mathrm{OCH}_{3}$.

$$
\begin{aligned}
& \mathrm{C}_{18} \mathrm{H}_{21} \mathrm{ON} \text {. Ber. C } 80.89, \mathrm{H} 7.86, \mathrm{~N} .24 . \\
& \text { Gef. " } 80.81, » 8.00, \$ 5.59 .
\end{aligned}
$$

Die Base wurde in viel verdünnter, kochender Salzsäure aufgelöst, und beim Erkalten fiel das Chlorhydrat in schönen, federförmigen, gelblichen Krystallen aus, die in Wasser sehr schwer löslich sind. Schmp. 218".

$$
\begin{aligned}
& \text { Ber. C } 71.17 \text {, H } 7.24 \text {. } \\
& \text { Gef. } 71.05 \text {, } 7.36 \text {. }
\end{aligned}
$$

Gold- und Platin-Salz zersetzten sich beim Umkrystallisiren und konnten deshalb nicht analysirt werden.

Da die reducirte Base am Stickstoff ein freies Wasserstoffatom hat, so war vorauszusehen, dass sie eine Benzoylverbindung bilden würde. Nach längerem Schütteln der Lösung der Base in Chloroform mit Benzoylchlorid und Natronlauge und Abdunsten des Chloroforms erhält man einen weissen Krystallkuchen, der aus Alkohol umkrystallisirt wurde. Beim Erkalten fiel die Benzoylverbindung in feinen, weissen Nadeln aus. Schmp. $97^{\circ}$.

$$
\begin{array}{r}
\mathrm{C}_{25} \mathrm{H}_{25} \mathrm{O}_{2} \mathrm{~N} \text {. ' Ber. C } 80.22, \mathrm{H} 6.96, \mathrm{~N} 3.77 . \\
\text { Gef. " } 80.27, 》 7.06, 》 4.12 .
\end{array}
$$

II. $p$-Methoxy- $\alpha$-Stilbazol.

Die Einwirkung von Anisaldehyd auf $\alpha$-Picolin ist schon von Sehuftan ${ }^{1}$ ) untersucht worden. Derselbe erhielt eine Base, die bei $97^{\circ}$ schmolz. Da indessen die Ausbeute sehr gering war, so konnte er nur das Platinsalz analysiren. Auf Grund dieser Analyse stellte er für die neue Base die Formel $\mathrm{C}_{5} \mathrm{H}_{4} \mathrm{~N} . \mathrm{CH}: \mathrm{CH} . \mathrm{C}_{6} \mathrm{H}_{4}\left(\mathrm{OCH}_{3}\right)$ auf

1) Diese Berichte 23, $2716[1890]$. 
nnd nannte sie Anisylidenpyridylalkin. Da ich bei der Einwirkung von Anisaldehyd auf Chinaldin überaus gute Ausbeuten erbalten hatte, so hielt ich es nicht für überflüssig, die Schuftan'schen Versuche zu wiederholen und seine Angaben mit grösseren Materialmengen zu ergänzen resp. zu berichtigen.

Ich erhitzte $10 \mathrm{~g} \alpha$-Picolin und $14 \mathrm{~g}$ Anisaldehyd unter Zusatz von etwas Chlorzink im zugeschmolzenen Rohr 10 Stunden lang auf $180-190^{\circ}$. Beim weiteren Verarbeiten des Röhreninhaltes zeigte es sich jedoch, dass die beiden Stoffe fast garnicht mit einander reagirt hatten. Erst nach 36-stündigem Erhitzen erhielt ich eine etwas bessere Ausbeute: $25 \mathrm{~g} \alpha$-Picolin and $40 \mathrm{~g}$ Anisaldehyd ergaben $2 \mathrm{~g}$ reine Base. Die Ausbeute war also immer noch recht schlecht, aber doch genügend, um die Base näher zu untersuchen.

Zur Gewinnung der Base wurde folgendermaassen verfahren: Der Röhreninhalt, der aus einem dicken, braunen Oele bestand, wurde mit verdünnnter Salzsäure ausgekocht, die Lösung mit Aether ausgeschüttelt und auf dem Wasserbade eingeengt. Beim Erkalten fiel das salzsaure Salz in feinen, gelben Nadeln aus, die in Wasser sehr leicht löslich sind. Aus der Lösung des salzsauren Salzes wurde die Base durch Kalilauge abgeschieden, wobei ein allzu grosser Ueberschuss von Kalilauge vermieden wurde, da sich die Base dadurch sehr leicht zersetzte. Dieselbe fiel in braunen Flocken aus, welche in Alkohol gelöst wurden. Da die Base in Alkohol, sowie in allen anderen Lösungsmitteln äusserst leicht löslich ist, so wurde zu der alkoholischen Lösung Wasser zugesetzt, bis eine Trübung entstand, die durch einige Tropfen Alkohol wieder beseitigt wurde. Indem nun der Alkohol langsam verdunstete, schied sich die Base, die in Wasser unlöslich ist, im Laufe von 2 Tagen in silberweissen, glänzenden Blättchen ab. Auf dieselbe Weise wurde sie noch 2 Mal umkrystallisirt, worauf sie analysenrein war. Schmp. $75^{\circ}$.

$$
\begin{aligned}
& \mathrm{C}_{14} \mathrm{H}_{13} \mathrm{ON} \text {. Ber. C 79.62, H 6.16, N 6.63. } \\
& \text { Gef. 》79.40, 》6.01，》7.01. }
\end{aligned}
$$

Das Chlorhydrat stellt, aus wenig heissem Wasser umkrystallisirt, feine, gelbe Nadeln dar. Schmp. 200-2010.

Ber. Cl 14.3. Gef. Cl 14.1.

Goldd op pelsalz. Orangefarbene Flocken, löslich in verdünnter Salzsäure. Schmp. $178^{\circ}$.

Ber. Au 35.8. Gef. Au 35.7.

Platindoppelsalz, löslich in verdünnter Salzsäure, fängt zu sintern an bei $225^{\circ}$ und ist bei $230^{\circ}$ geschmolzen.

Ber. Pt 23.41. Gef. Pt 23.53.

Schuftan giebt für seine Base den Schmp. $97^{\circ}$, sowie für sein Platinsalz den Schmp. $189^{\circ}$ an und nimmt auf Grund der Analyse 
des Platinsalzes an, dass die beiden Körper unter Wasseraustritt mit einander reagirt haben. Dasselbe habe auch ich durch Analyse der Base und dreier Salze constatiren können, habe aber als Schmelzpunkt für meine Base $75^{\circ}$, für das Platinsalz $230^{\circ}$ gefunden. Bei der geringen Menge Substanz, die Schuftan unter den Händen gehabt hat, ist es leicht möglich, dass dieselbe nicht ganz rein war, und ich glaube, dass seine Angaben nach den meinigen zu corrigiren sind.

Auch diese Base versuchte ich zu reduciren. In einem geräumigen Rundkolben wurden $20 \mathrm{~g}$ Natrium auf dem Wasserbade erhitzt. $3.5 \mathrm{~g}$ reine Base wurden in kochendem, absolutem Alkohol gelöst und die Lösung auf das erhitzte Natrium gegossen, worauf sofort eine stürmische Reaction begann. Sobald diese nachliess, wurde siedender Alkohol nachgegossen, bis das Natrium verschwunden war. Der Kolbeninhalt wurde nun mit Wasser versetzt und der Alkohol abdestillirt. Auf der zurückbleibenden Flüssigkeit schwamm die Base als gelbliches Oel, welches mit A ther aufgenommen wurde. Nach dem Verdunsten des Aethers hinterblieb ein gelbes Oel, welches ich wegen der geringen Menge nicht destilliren konnte. Ich rersuchte daher nur, Salze der Base darzustellen.

Das Chlorhydrat fiel nach dem Lösen der Base in verdünnter Salzsäure in weissen Nadeln aus. Schmp. $173^{\circ}$.

$$
\begin{aligned}
& \text { Ber. C } 65.75 \text {, H } 8.61 \text {. } \\
& \text { Gef. 》 65.55, 》 } 8.75 \text {. }
\end{aligned}
$$

Gold- und Platin-Salz, sowie das Quecksilbersalz fielen als schmierige Oele aus und konnten nicht näher untersucht werden.

$$
\text { III. } p \text {-Methoxy- } \beta^{\prime} \text {-äthyl- } \alpha-\text { stilbazol. }
$$

Das als Ausgangsmaterial genommene Aldehydcollidin wurde nach der von $\mathrm{Bach}^{1}$ ) angegebenen Methode dargestellt.

$10 \mathrm{~g}$ Collidin und $12 \mathrm{~g}$ Anisaldehyd wurden unter Zusatz von etwas Chlorzink im zugeschmolzenen Rohr 10 Stunden lang auf $180^{\circ}$ erhitzt. Beim Oeffnen der Röhre war kein Druck bemerkbar, der Inhalt bestand aus einem dicken, braunen Oele, das abgespaltene Wasser war sichtbar. Der Röhreninhalt wurde mit Salzsäure ausgekocht und von den Schmieren, die sich gebildet batten, abfiltrirt. Beim Erkalten fiel eine geringe Menge des Cblorhydrats in feinen, gelben Nadeln aus. $\mathrm{Da}$ aber die Menge zur Analyse nicht genügte, so wurden nur das Gold- und Platin-Salz näher untersucht.

Das Goldsalz bildet einen orangefarbenen Niederschlag, der mehrere Male ans Alkohol umkrystallisirt wurde. Es sintert bei $132^{\circ}$ und ist bei $137^{\circ}$ geschmolzen.

Ber. Au 34.07. Gef. Au 34.2.

1) Inaug.-Dissertation, Breslau 1901. 
Das Platinsalz fällt, aus heissem Alkohol umkrystallisirt, in feinen, gelben Nadeln aus. Schmp. 2010.

Ber. Pt 21.92. Gef. Pt 21.72.

Aus diesen Analysen geht hervor, dass die beiden Körper unter Wasseraustritt mit einander in Reaction getreten sind. Die entstandene Base hat also die Formel:

$\mathrm{C}_{2} \mathrm{H}_{5} \cdot \mathrm{C}_{5} \mathrm{H}_{3} \mathrm{~N} . \mathrm{CH}: \mathrm{CH} . \mathrm{C}_{6} \mathrm{H}_{4}\left(\mathrm{OCH}_{3}\right)$.

469. R. Knick: Ueber die Condensation von $\alpha, \gamma$-Lutidin mit $p$-Nitrobenzaldehyd.

[Aus dem chemischen Institut der Universităt Breslau.]

(Eingegangen am 14. Juli 1902.)

Auf Veranlassung des Hrn. Geh.-Rath Ladenburg unternahm ich es, $\alpha, \gamma$-Lutidin mit $p$-Nitrobenzaldehyd zu condensiren, wie ich es beim $\alpha$-Picolin bereits beschrieben habe ${ }^{1}$ ). Je $5 \mathrm{~g}$ reines $\alpha, \gamma$-Lutidin, das nach der von $\mathrm{Ladenburg}^{2}$ ) angegebenen Reinigungsmethode aus dem Rohlutidin gewonnen war, wurden mit $6 \mathrm{~g} p$-Nitrobenzaldehyd und $6 \mathrm{~g}$ Wasser im Einschmelzrohr auf $130-135^{\circ} 10$ Stunden lang erhitzt. Das Reactionsproduct stellte eine durch Schmieren stark braun gefärbte, harzartige Masse dar, die ich in verdünnter Salzsäure zu lösen versuchte. Ein Theil löste sich nicht; diesen filtrirte ich ab, wusch das anf dem Filter zurückbleibende gelbe Pulver mit Aether aus und löste es durch Kochen mit sehr viel Wasser. Es schieden sich bei der Abkühlung kleine gelbe Nadeln aus, die noch mehrmals umkrystallisirt und dann mit Kali zerlegt wurden. Ein dunkelgelber Niederschlag fiel aus, dessen Analyse nach dem Absaugen und mehrmaligen Umkrystallisiren aus Alkohol ergab, dass bei der Condensation die eine Methylgruppe des Lutidins mit dem Aldehyd unter Abspaltung ron Wasser und Bildung des Stilbazolkörpers in Reaction getreten war nach folgender Gleichung:

$$
\begin{aligned}
\mathrm{C}_{5} \mathrm{H}_{3} \mathrm{~N}<\mathrm{CH}_{3}+(\mathrm{OHC}) & \left(\mathrm{NO}_{2}\right) \mathrm{C}_{6} \mathrm{H}_{4} \\
= & \mathrm{C}_{5} \mathrm{H}_{3} \mathrm{~N}< \\
\mathrm{CH}_{3}: \mathrm{CH} . \mathrm{C}_{6} \mathrm{H}_{4} \cdot \mathrm{NO} & \mathrm{CH}_{2}+\mathrm{H}_{2} \mathrm{O} .
\end{aligned}
$$

$\mathrm{Zu}$ dem Filtrate des in Wasser unlöslichen, salzsauren Stilbazols fügte ich Natronlauge hinzu. Den hierbei sich abscheidenden flockigen Niedersehlag, der noch durch kleine Mengen des Stilbazolkörpers verunreinigt war, löste ich in ziemlich concentrirter, kalter Salzsäure. Die ungelösten Bestandtheile entfernte ich durch Filtrieren und erhielt
1) Diese Beriehte 35, 1162 [1902].
2) Ann. d. Chem. 247, 35. 